\title{
O BRASIL DE SÉRGIO BUARQUE DE HOLANDA: Do patrimonialismo à democracia
}

\section{Luzia Helena Herrmann de Oliveira}

Professora-adjunta do Departamento de Ciências Sociais da Universidade Estadual de

Londrina

Este artigo procura apresentar e problematizar possíveis leituras de Raízes do Brasil, destacando alguns textos recentemente publicados que se fundamentam nesta obra clássica com o intuito de interpretar o Brasil da atualidade.

"A visão conservadora das coisas como um todo é semelhante ao tipo de quadro inclusivo que se poderia obter de uma casa examinandoa de todos os lados possíveis, uma visão concreta da casa em todos os seus detalhes a partir de todos os ângulos. Mas o progressista não está interessado em todos esses detalhes; ele vai direto à planta da casa e a sua visão é mais adequada à análise racional do que à representação intuitiva. E dentro dessa diferença nos modos de situar as coisas individuais em seus contextos mais amplos, existe uma diferença ainda mais radical entre o padrão de experiência conservador e o progressista - desta vez, uma diferença no modo de experimentar o tempo". MANNHEIM, Karl, O Significado do Conservantismo.

$\mathbf{E}$ m um texto publicado durante a década de 70 , Umberto Eco afirmava que a obra aberta, diferentemente do discurso persuasivo, abre a possibilidade para múltiplas interpretações, uma vez que não nos obriga a vê-la de um modo predeterminado. Segundo ele, é próprio da obra aberta sugerir caminhos que não são explicitados em forma de mensagem e, assim, permanecer como resposta a "diversos tipos de sensibilidade e de cultura".

Tomando-se por este prisma, o livro Raízes do Brasil, de Sérgio Buarque de Holanda, insere-se com certeza neste caso. No que se refere à permanência, basta lembrar que foi escrito em 1936 mas, ainda hoje, é fonte segura de citação sempre que se pretende discutir nossas possibilidades democráticas ${ }^{1}$. No que se refere às possíveis interpretações, um breve levantamento bibliográfico demonstraria a quantidade e diversidade teórica de artigos atuais que se fundamentam em suas análises. Pode-se mesmo afirmar que a "autoridade teórica" de Sérgio Buarque Holanda tem levado a uma ampla gama de interpretações que, em alguns casos,

1 O livro foi lançado em 1936, recebendo em 1997 sua $27^{\text {a }}$ edição. As citações deste artigo foram retiradas da $25^{\mathrm{a}}$ edição: HOLANDA, Sérgio. Raízes do Brasil. São Paulo: Companhia das Letras, 1995. chegam a ser divergentes ${ }^{2}$.

Com este artigo, meu objetivo é analisar as idéias de Sérgio Buarque por uma perspectiva atual, procurando compreender como uma parcela dos cientistas sociais da atualidade vêm se apropriando delas. Pretendo, portanto, abordar uma questão que, apesar de suas implicações teóricas e políticas, permanece pouco discutida: quais os veios que prendem essas recentes "intervenções" à obra de Sérgio Buarque e, dentro de uma leitura mais pontual, que aspectos do pensamento do autor têm sido valorizados nessas interpretações?

\section{Raízes do Brasil - uma interpretação:}

Em Raízes do Brasil, parece-me importante destacar

\footnotetext{
2 Vale citar como exemplo os artigos de COSTA, Valeriano Mendes Ferreira. Vertentes Democráticas em Gilberto Freire e Sérgio Buarque de Holanda, Lua Nova, 26: 219-248, 1992 e REZENDE, Maria José de. A democracia em Gilberto Freire e Sérgio Buarque de Holanda, Plural: Sociologia. USP, São Paulo, 3:14-48, 1. sem. 1996 que, apesar da semelhança nos títulos, apresentam visões bastante diferentes das obras em pauta.
} 
o diálogo que Sérgio Buarque de Holanda estabelece com Weber, quando apresenta as diferenças entre as nossas tradições ibéricas e a cultura anglo-saxã e quando responde, de modo extremamente criativo, ao dilema político de que "um certo mínimo de vontade de obedecer, isto é, de interesse (externo ou interno) na obediência, faz parte de toda relação autêntica de dominação" (WEBER, 1994: 139)³.

Analisando a realidade política do país durante os anos 30 , em que as teorias liberal e autoritária disputavam entre si a primazia de resolver os problemas institucionais e políticos do país, Sérgio Buarque desenvolve a tese de que ambas se apresentavam como soluções igualmente "superficiais e enganadoras", uma vez que eram incapazes de atingir o cerne da questão, qual seja, promover "transformações complexas e verdadeiramente estruturais na vida da sociedade" (HOLANDA,1995:178).

Para Sérgio Buarque, a organização política brasileira deve ser compreendida a partir de nossas raízes históricas e culturais, levando-se em conta as formas específicas da colonização ibérica que, segundo ele, primou pela "cultura da personalidade, que parece constituir o traço mais decisivo na evolução da gente hispânica, desde os tempos imemoriais" (Idem:32). Por serem adeptos de uma filosofia em que o mérito e a responsabilidade individual foram sempre consideradas virtudes verdadeiramente nobres e permanentes dos indivíduos, os povos ibéricos valorizam, acima de tudo, a coragem e cultivam o espírito de aventura: "existe uma ética do trabalho, como existe a ética da aventura. Assim, o indivíduo do tipo trabalhador só atribuirá valor moral positivo às ações que sente ânimo de praticar e, inversamente, terá por imorais e detestáveis as qualidades próprias do aventureiro - audácia, imprevidência, irresponsabilidade, instabilidade, vagabundagem - tudo, enfim, quanto se relacione com a concepção espaçosa do mundo, característica desse tipo" (Idem: 44).

São essas qualidades que ajudam a explicar o que levou os hispânicos à conquista dos novos continentes: "o que o português vinha buscar era, sem dúvida, a riqueza, mas riqueza que custa ousadia, não riqueza que custa trabalho" (Idem: 49). E mostra, também, as peculiaridades dessa civilização construída por eles: "o princípio que, desde os tempos mais remotos da colonização, norteara a criação de riquezas no país não deixou de valer um só momento para a criação agrária. Todos queriam extrair do solo excessivos benefícios sem grandes sacrifícios. Ou, como já dizia o mais antigo de nossos historiadores, queriam servir-se da terra, não como senhores, mas como usufrutuários, 'só para a desfrutarem e a deixarem destruída"” (Idem: 52).

Segundo Sérgio Buarque, não se desenvolveram no Brasil "as idéias de solidariedade" que o tipo racional estimularia, porque os povos ibéricos demonstraram dificuldades em aceitar os princípios desenvolvidos no seio das culturas calvinistas: "é compreensível, assim, que jamais tenha se naturalizado entre gente hispânica a moderna religião do trabalho e o apreço à atividade utilitária. Uma digna ociosidade sempre pareceu mais excelente, e até mais nobilitante, a um bom português, ou a um espanhol, do que a luta insana pelo pão de cada dia (...) O que entre elas (nações ibéricas) predomina é a concepção antiga de que o ócio importa mais que o negócio e de que a atividade produtora é, em si, menos valiosa que a contemplação e o amor" (Idem:38).

Na realidade, Sérgio Buarque acredita que esse culto à personalidade pôde desenvolver-se em virtude da "reduzida capacidade de organização social" vigente na época. Entre portugueses e espanhóis, a única solidariedade observável era a que se fundava em "vinculação de sentimentos" e, portanto, uma forma muito diversa da solidariedade organizada segundo uma moral do trabalho, que "estimula a organização racional dos homens e sustenta a coesão entre eles". Contrariamente, essa solidariedade familiar e de amigos, que cria "círculos forçosamente restritos, particularistas", não estimula a ordem e harmonia na sociedade e, por conseguinte, necessita de algum valor que seja capaz de manter a coesão social. É assim que Sérgio Buarque explica no último tópico do Capítulo Um, cujo subtítulo é "a obediência como fundamento de disciplina", como se estabelece o consentimento político entre os povos de colonização ibérica: " a autarquia do indivíduo, à exaltação extrema da personalidade, paixão fundamental e que não tolera compromissos, só pode haver uma alternativa: a renúncia a essa mesma personalidade em vista de um bem maior. (...) A vontade de mandar e a disposição para cumprir ordens sãolhes igualmente peculiares. As ditaduras e o Santo Ofício parecem constituir formas tão típicas de seu caráter como a inclinação à anarquia e à desordem. Não existe, a seu ver, outra sorte de disciplina perfeitamente concebível, além da que se funde na excessiva centralização do poder e na obediência” (Idem: 39).

Nos capítulos centrais do livro, Sérgio Buarque fala como esses valores foram sendo assentados às formas mais concretas do relacionamento social brasileiro. É no Capítulo III, quando discorre sobre "a herança rural", que se define mais claramente por que essa relação de mando-obediência encontrou campo fértil no Brasil: "nos domínios rurais, a autoridade do proprietário de terras não sofria réplicas. Tudo se fazia consoante sua vontade, muitas vezes caprichosa e despótica. (...) nos domínios rurais é o tipo de família organizada segundo as normas clássicas do velho direito romano-canônico, mantidas na península Ibérica através de inúmeras gerações, que prevalece como base e centro de toda organização. Os escravos das plantações e das casas, e não somente escravos, como os agregados, dilatam o círculo familiar e, com ele, a autoridade imensa do pater-famílias" (Idem: 80/81).

Em todo o capítulo é desenvolvida a teoria de que essa esfera doméstica vertical e opressiva ampliou-se a ponto de constituir a própria sociedade política no Brasil: "o quadro familiar torna-se tão poderoso e exigente, que sua sombra persegue os indivíduos mesmo fora do recinto doméstico. A entidade privada precede sempre, neles, a entidade pública. A nostalgia dessa organização compacta, única e intransferível, onde prevalecem necessariamente as preferências fundadas em laços afetivos, não podia deixar de marcar nossa sociedade, nossa vida pública, todas as nossas atividades. (...) O resultado era predominarem, em toda a vida social, sentimentos próprios à comunidade 
doméstica, naturalmente particularista e antipolítica, uma invasão do público pelo privado, do Estado pela família" (Idem:82).

Trata-se, sem dúvida, de um caso típico-ideal de sociedade patrimonialista estudada por Weber, em que "a dominação tradicional costuma atuar sobre as formas de gestão econômica, em primeiro lugar e de modo muito geral, mediante um certo fortalecimento das idéias tradicionais" (WEBER, 1994:156). Isso Sérgio Buarque deixa claro pelas inúmeras vezes que nos remete a Weber e pelas comparações que faz entre o Brasil e outras sociedades, racionalmente organizadas: "esse paternalismo (brasileiro) é tudo quanto se poderia esperar de mais oposto, não já às idéias de França revolucionária, esses ópios políticos, como lhes chamou acrimoniosamente o mesmo Silva Lisboa, mas aos próprios princípios que guiaram os homens de estado norteamericanos na fundação e constituição de sua grande República. Pois não foi um desses homens, James Madison, quem sustentou a impotência dos motivos morais e religiosos na repressão das causas de dissídio entre os cidadãos, e apresentou como finalidade precípua dos governos finalidade de onde resultaria certamente sua natureza essencial - a fiscalização e o ajuste de interesses econômicos divergentes?" (HOLANDA, op. cit.:85)

Explica-se assim o dilema weberiano de "por que obedecer": "esteriotipada por longos anos de vida rural, a mentalidade da casa-grande invadiu assim as cidades e conquistou todas as profissões, sem exclusão das mais humildes" (Idem:87). Para Sérgio Buarque, a estrutura sócioeconômica e, de modo mais específico, a forma como se desenvolveu a propriedade da terra no país, mostra-se um fator preponderante na manutenção e reprodução das instituições políticas autoritárias e dos valores culturais tradicionais. Somente essa visão totalizante do pensamento do autor permite compreender como é possível o livro terminar com uma proposta otimista de "revolução brasileira" e entender como, desde os primeiros capítulos, essa idéia se insinua.

Em sua opinião, as estruturas arcaicas da sociedade brasileira começaram a desmoronar quando o trabalho escravo foi substituído pelo trabalho assalariado, dando início, assim, à constituição de uma "nova composição social" que apontava para uma "revolução lenta, mas segura e concertada" na vida política e social brasileira. Ou seja, para Sérgio Buarque, as mudanças meramente políticas não seriam capazes, por si só, de provocar alterações substantivas no modo brasileiro de relacionamento social porque faltavam, naquele momento, os pressupostos básicos de uma verdadeira transformação. Os fundamentos sociais da igualdade jurídica não estavam presentes na realidade brasileira e, desta forma, todas as soluções políticas

\footnotetext{
3 Sérgio Buarque viveu na Alemanha entre julho de 1929 a dezembro de 1930, trabalhando para O Jornal, do Rio de Janeiro. Descrevendo esse período, Antonio Cândido salienta a grande influência intelectual que a cultura alemã exerceu sobre o autor. Para Antonio Cândido, Raízes... pode ser considerado um livro "meio alemão" (CANDIDO, Antonio. Sérgio em Berlim e depois (Introdução). In: BARBOSA Francisco de Assis (org.). Raízes (de Sérgio Buarque de Holanda). Rio de Janeiro: Rocco, 1989).
}

apresentadas - liberalismo ou caudilhismo - mostravam-se igualmente "a-históricas".

$\mathrm{Na}$ visão de Sérgio Buarque, uma verdadeira revolução brasileira dependeria de mudanças mais profundas, mais estruturais, como aquelas que vieram alterar todo o sistema social e que levaram o "centro de gravidade não já nos domínios rurais, mas nos centros urbanos" (Idem: 172) Como enfatiza Sérgio Buarque, trata-se de "processo demorado e que vem durando pelo menos três quartos de século (...) Se o movimento que, através de todo o Império, não cessou de subverter as bases em que assentava nossa sociedade ainda está longe, talvez, de ter atingido o desenlace final, parece indiscutível que já entramos em sua fase aguda" (Idem: 172). Deixa claro, assim, que as mudanças vêm da própria base social. São mudanças lentas, constitutivas, mas que a olhos vistos se processam.

Nos parágrafos finais do livro, quando fala sobre a "nossa revolução", reforça a idéia de que a revolução democrática "não será, talvez, a das convulsões catastróficas, que procuram transformar de um mortal golpe, e segundo preceitos de antemão formulados, os valores longamente estabelecidos. É possível que algumas de suas fases culminantes já tenham sido ultrapassadas, sem que possamos avaliar desde já sua importância transcendente. Estaríamos vivendo assim entre dois mundos: um definitivamente morto e outro que luta por vir 'a luz". (Idem: 180)

E que mundo seria esse? Com certeza, alguma coisa muito diversa do relacionamento socialmente vertical e politicamente privatístico que se desenvolvia na sociedade de então. Com certeza, seriam mudanças sustentadas (ou legitimadas) pelos próprios segmentos sociais oprimidos, alíás, como foram e continuam sendo feitas todas as revoluções políticas historicamente conhecidas. Concluindo, essas mudanças seriam concretizáveis exatamente em virtude dessas transformações sociais, que tornariam possível o rompimento de um tipo de dominação que tinha como fundamento "a vontade de mandar e a disposição em cumprir ordens" (Idem: 39).

\section{Estado e Sociedade no Brasil Atual}

Na atualidade, as idéias de Sérgio Buarque continuam servindo como sustentação teórica às interpretações políticas do Brasil. Diferentemente desse autor, contudo, a maior parte desses estudos recentes caracteriza-se por um profundo pessimismo e por uma incapacidade de vislumbrar perspectivas de transformação da política brasileira. Fundamentando-se em Sérgio Buarque, cientistas sociais da atualidade têm procurado demonstrar que a sociedade brasileira apresenta peculiaridades que impedem a construção da democracia, tal como foi institucionalmente idealizada pelos iluministas no século XVIII. Ou seja, repetindo os termos do livro, para essa parcela da intelectualidade, a democracia sempre foi - e continuará sendo - um lamentável mal entendido. ${ }^{4}$

\footnotetext{
4 A citação correta de Sérgio Buarque é: "A democracia no Brasil sempre foi um lamentável mal entendido" (Idem:160).
} 
Observando-se mais atentamente esses textos, percebemos que os atuais intérpretes sempre tomam um dos vários atalhos sugeridos no livro de Sérgio Buarque. É o que acontece, por exemplo, em certo tipo de análise que privilegia os traços culturais deixados pelos povos ibéricos. Dentro desta linha de raciocínio, são enfatizadas as diferenças entre a "cordialidade" vigente em nosso relacionamento e uma pretensa "racionalidade" que nos são estranhas. Nesse caso, a política, para o bem e para o mal, torna-se refém deste modo de ser eminentemente personalista e emocional, que se encontra muito distante de uma organização política efetivamente democrática: "desconfiada, a massa espreita. Descrê dos partidos e dos políticos em geral. Anseia pelo líder, pelo salvador, pelo condutor de ilusões. Aqui e ali, desponta alguém capaz de manter acesa a esperança, ainda que as desilusões se sucedam. O espetáculo tem que continuar. E continua de maneira privilegiada, envolvente, festiva, através dos modernos palanques eletrônicos. Agora, a política está no ar” (BARBOSA, 1988:86). “O país é pródigo em políticas contraditórias, como se o peso de sua formação histórica e cultural sempre mantivesse presos na mentalidade do atraso os possíveis avanços no sentido do desenvolvimento". (BARBOSA, 1995:401)

Seja pelo lado matreiro da malandragem, seja pela despolitização do favor político, segundo Maria Lúcia Victor Barbosa, a sociedade brasileira possui um modo próprio do qual não é possível fugir. E, dentro desse círculo vicioso em que a tradição cultural preserva o atraso político e o atraso político preserva a tradição cultural, não parece haver escapatória.

Nos trechos citados, Maria Lúcia apega-se mais aos aspectos culturalistas de Raízes..., mas existe uma outra vertente interpretativa que prefere retirar do livro a enfática explanação de Sérgio Buarque sobre as relações sociais de mando-obediência tradicionais da história do Brasil. Segundo estes analistas, essas relações definiriam uma forma específica de regime autocrático que se mantém na atualidade.

Analisando Raízes..., Maria José de Rezende afirma que, segundo Sérgio Buarque, "nossas raízes políticas eram totalmente desabonadoras no sentido da democratização: o grupo familiar não conhecia restrições, o pátrio poder era ilimitado, a entidade privada sempre prevalecia e, por sua vez, impossibilitava a publicização das relações sociais, o que deveria ser o suporte da democracia" (REZENDE, 1996:34). Nessa passagem, a autora toma por base a referência de Sérgio Buarque ao tipo de dominação patriarcal de que tratou Weber: a existência da casa grande e da senzala criaram uma interdependência rigidamente hierarquizada, violenta, opressiva, que "contaminou todos os aspectos da vida social" 5 .

Nesta ótica, como o arbítrio é a condição normal do relacionamento social brasileiro, inexistiria no país segmentos sociais capazes de realizar a tarefa da mudança política. Nesse sentido, o Brasil tem encontrado enorme dificuldade para publicizar a política, que se manteve - e se mantém - como o

5 Citação de Raízes do Brasil, transcrita de REZENDE, M. J. de. op. cit., p. 34 . locus do domínio privado. Embora Maria José demonstre grande ceticismo quanto a nossas futuras possibilidades democráticas, pode-se afirmar que, em sua visão, há alguma perspectiva de mudança: "o Brasil não estaria condenado à não-democracia, mas os obstáculos seriam imensos" (REZENDE, op. cit.: 35). Mas nem essa pequena possibilidade aparece na análise de Marilena Chauí, que segue a mesma linha de raciocínio: "a estrutura autoritária não permite o surgimento das instituições democráticas (...) se a democracia é a condição para suplantar a teologia política, não temos como suplantá-la" (CHAUÍ, 1994:28).

Marilena Chauí inspira-se em Visão do Paraíso, do mesmo Sérgio Buarque, para explicar que o paradigma autoritário ainda permanece na sociedade brasileira, em virtude da existência de um "mito fundador" que "se conserva como perenemente presente", sustentando as ideologias políticas de dominação (CHAUÍ, op. cit.: 21$)^{6}$. Retirando de Sérgio Buarque a idéia de que os colonizadores da América foram atraídos pela visão paradisíaca de que as novas terras seriam uma cópia dos Jardins do Éden, Chauí vai além, afirmando que este modelo permanece presente, juntamente a um messianismo herético que se mostrou bastante apropriado à domestificação das classes miseráveis e a uma tradição histórica providencialista, herdada de Sto. Agostinho, que pretende transformar a história na realização da vontade divina. ${ }^{7}$

Para Chauí, são características deste modelo: 1) a predominância do contato direto entre governante e governados, sem a medição dos corpos intermediários; 2) a permanência das relações de tutela, de favor, em detrimento da conquista dos direitos; 3) a predominância do poder baseado na "vontade pessoal e arbitrária do chefe, não havendo a esfera pública da lei e do direito como fundamentos coletivos do poder" (Idem:20); 4) a personificação do poder, nos moldes da dominação carismática weberiana; 5) a presença de um poder autocrático em seu "exercício" e "forma" (Idem:21); 6) a definição de uma forma paradigmática de autoritarismo político que invade todas as esferas de poder. Ou seja, mais uma vez nos reportamos aos limites do domínio patriarcal e a uma forma eminentemente desigualitária de relacionamento social.

Como se vê, os autores abordados tendem a privilegiar os aspectos negativos apontados por Sérgio Buarque e fazer com que o leque de nossas possibilidades históricas seja demasiadamente estreitado. Contudo, apesar da manifesta filiação teórica, um paralelo com Raízes... demonstra que

\footnotetext{
6 De fato, Chauí não chega a citar Raízes do Brasil, mas sim Visão do Paraíso (São Paulo: Companhia Editora Nacional, 2. ed., 1969). No entanto, pela similaridade entre sua análise e a esta que vem sendo apresentada aqui, acredito que seja perfeitamente válido enquadrá-la como uma continuadora desta linha de Raízes...

7 Como Sérgio Buarque deixa claro, Visão do Paraíso não diz respeito ao Brasil atual: "...bem poderia servir estudo semelhante como introdução à abordagem de alguns fundamentos remotos da própria história do Brasil, e de outro - em que não se tocou nestas páginas como contribuição para a boa inteligência de aspectos de nossa formação nacional ainda atuantes nos dias de hoje." (HOLANDA, 1969: XI)
} 
esses estudos recentes apresentam uma diferença fundamental, uma vez que não é possível encontrar-se neles a original unidade entre estrutura social e representações simbólicas. Em Sérgio Buarque, as determinações causais são entrecruzadas: estrutura sócio-econômica, valores, instituições, formam um todo de múltiplas influências. Para ele, a colonização ibérica trouxe um determinado modo de cultura, de produção econômica, de instituições políticas, cuja desagregação acabaria por interferir na reorganização do todo.

Nos textos mais recentes, a original unidade interpretativa foi desfeita porque, primeiro, o Brasil obviamente não é mais um país rural e, segundo, porque a cultura sofreu um profundo enriquecimento (se ainda persistem traços ibéricos, estes devem conviver com a multiplicidade cultural e étnica em que se constitui o país na atualidade). Além disso, um aspecto sempre desprezado nessas interpretações é o peso político advindo da desagregação da sociedade patriarcal ou, noutras palavras, a importância do fator consentimento no conflito entre forças políticas.

Uma rápida passada de olhos pela história brasileira deste século demonstra que, no pós 30 , a conquista da obediência ao poder autoritário tornou-se, no mínimo, bem mais difícil. Para se impor, o poder autoritário precisou utilizar - com uma frequiência cada vez maior e durante períodos cada vez mais longos - do método da coação física. Tivemos rupturas institucionais de 1930 a 1934 , de 1937 a 1945, de 1964 a 1985. Do lado oposto, avaliando-se os interregnos democráticos, estudos sobre a chamada democracia populista demonstram que (mesmo levando-se em conta o baixo grau de organização partidária da população) o peso político das massas urbanas foi relevante para o atendimento a uma série de demandas populares ${ }^{8}$. Essa é uma das constatações de Lafer, quando analisa o colapso do pacto de dominação populista ocorrido em 1964: "o sistema político pós-64, pelas características de seu pacto de dominação e da coligação de forças que o sustenta, pela desvalorização da moeda da popularidade eleitoral e por aquilo tudo que isto implica em termos de poder, foi capaz de ampliar este limite (de sua capacidade extrativa), diminuindo o atendimento de demandas que a República Populista não podia ignorar." (LAFER, 1975: 80).

Segundo Lafer, a opção do sistema militar pela legitimidade negativa da coação física e pela legitimidade positiva da racionalidade econômica, "funcionou bastante bem" do ponto de vista técnico, mas os custos pelo abandono da moeda do voto foram altos para a sociedade brasileira: "custos políticos em termos de supressão de liberdades públicas; custos sociais em termos de acentuadas desigualdades na distribuição de renda, para a qual deve ter certamente contribuído a forte contenção inicial dos reajustes salariais; custos culturais em termos de um amortecimento da criatividade, produto inevitável do controle coercitivo da criação..." (Idem:101) Nesse caso, o fundamento coercitivo do poder foi um elemento básico daquele pacto de dominação autoritário que não se sustentou pelo consentimento da maioria.

Desde então, são cada vez mais abundantes os exemplos em que poderíamos nos deter para demonstrar que o Brasil mudou, já não prevalecendo um substrato social que seja capaz de manter a legitimidade da coação tradicional patrimonialista. Pelo contrário, pesquisas recentes têm demonstrado mudanças na cultura política brasileira, fazendo crer que amadurecem no seio da sociedade os princípios democráticos de participação popular ${ }^{9}$.

É certo que, sem dificuldades, ainda podemos encontrar inúmeros exemplos do atraso que permanece incrustado em nossas instituições políticas, assim como é claro que nos recantos da sociedade brasileira pululam exemplos demonstrativos de nossos vícios patriarcais. Ocorre que, como bem explicou Sérgio Buarque, as mudanças não acontecem através de rupturas violentas e profiláticas. O novo chega imiscuindo-se no velho e muitas vezes não sendo percebido. Trata-se de um longo processo.

Sendo assim, o que verdadeiramente importa é precisar esse momento social e político que estamos vivendo, uma vez que na posição de cientistas sociais nosso objetivo é desvendar a realidade. Meu ponto de vista - que não é apenas meu - é que a sobrevalorização dos aspectos tradicionais da política dificulta a percepção da mudança. Além disso, fica bastante difícil visualizar a transformação quando observamos que a maior parte da intelectualidade, justamente aquela parcela da sociedade que deve instigar o debate público com propostas transformadoras, permanece atada a uma visão conservadora.

Antonio Cândido, em uma das análises mais lúcidas sobre Raízes..., afirma que a obra dá margem a duas leituras: "o livro é ao mesmo tempo uma análise do passado (que pegou mais) e uma proposta revolucionária de transformação do presente (que pegou menos)" (CANDIDO, op. cit.:125). Para Antonio Cândido, a atualidade de Sérgio Buarque devese exatamente a esta percepção articulada entre o passado e o futuro, em que a democracia popular aparece como desfecho.

Passadas algumas décadas desde a publicação de Raízes... e considerando-se as mudanças estruturais, culturais e institucionais ocorridas no país, atualmente, analisando-se a "planta da casa" em que se transformou o Brasil, já não teria chegado o tempo de nos voltarmos para esta segunda e possível leitura?

8 Dois trabalhos clássicos sobre o período do populismo brasileiro são: WEFFORT, Francisco Corrêa. O populismo na política brasileira. Rio de Janeiro: Paz e Terra, 1978 e SOARES, Gláucio Ari Dillon. Sociedade e Política no Brasil. São Paulo: Difel, 1973.

\footnotetext{
9 Ver, especialmente: MOISÉS, José Álvaro. Os brasileiros e a
} democracia. São Paulo: Ática, 1995. 


\section{BARBOSA, Maria Lúcia Victor. O Voto da Pobreza e a}

Pobreza do Voto. Rio de Janeiro: Zahar, 1988.

. América Latina: em busca do paraíso perdido. São Paulo: Saraiva, 1995;

CANDIDO, Antonio. Sérgio em Berlim e depois (Introdução). In: BARBOSA, Francisco de Assis (org.). Raízes (de Sérgio Buarque de Holanda). Rio de Janeiro: Rocco, 1989;

CHAUÍ, Marilena. Raízes teológicas do populismo no Brasil: teocracia dos dominantes, messianismo dos dominados. In: DAGNINO, Evelina (org.). Anos 90 - Política e Sociedade no Brasil. São Paulo: Brasiliense, 1994;

COSTA, Valeriano Mendes Ferreira. Vertentes Democráticas em Gilberto Freire e Sérgio Buarque de Holanda, Lua Nova, 26: 219-248, 1992;

HOLANDA, Sérgio. Raízes do Brasil. São Paulo: Companhia das Letras, 1995;

Visão do Paraíso. São Paulo: Companhia Editora Nacional, 2. ed., 1969;

LAFER, Celso. O Sistema Político Brasileiro. São Paulo: Perspectiva, 1975;

MOISÉS, José Álvaro. Os brasileiros e a democracia. São Paulo: Ática, 1995;

REZENDE, Maria José de. A democracia em Gilberto Freire e Sérgio Buarque de Holanda, Plural: Sociologia. USP, São Paulo, 3:14-48, 1. sem. 1996;

SOARES, Glaucio Ari Dillon. Sociedade e Política no Brasil. São Paulo: Difel, 1973;

WEBER, Max.Economia e Sociedade. Brasília: UnB, 1994. $3^{\mathrm{a}}$ edição;

WEFFORT, Francisco Corrêa. O populismo na política brasileira. Rio de Janeiro: Paz e Terra, 1978. 